\title{
A pilot study of children with amblyopia treated by the gratings method
}

\author{
J. D. A. CARRUthers, J. A. PRATt-JOHNSON, And G. TIllson \\ From the Department of Ophthalmology, University of British Columbia, and \\ Vancouver General Hospital, Division of Paediatric Ophthalmology, Vancouver, BC, Canada
}

SUMMARY A total of 6 patients, 2 with anisometropic, 2 with strabismic and anisometropic, and 2 with strabismic amblyopia treated with the 'gratings method' showed more than 2 lines of improvement in linear visual acuity. Patient attention and interest and repeated testing of the visual acuity were uncontrolled factors in this study. Moreover, the detailed visual tasks performed by the amblyopic eye may in themselves be the reason for improvement. Clearly a careful study which controls these possibilities is needed before a claim can be made that the 'gratings' per se offer an improved method of treatment of amblyopia.

Great interest was aroused by the reports from Addenbrooke's Hospital and the Physiological Laboratory, University of Cambridge, of a new treatment for amblyopia. ${ }^{1-4}$ We carried out a pilot study, without controls, of 30 children with amblyopia who were treated by this method. Twenty of these patients had had a poor response to treatment by conventional occlusion methods (group A) and 10 were previously untreated amblyopes (group B).

\section{Patients and methods}

Our study tried to follow as exactly as possible the method described by the Cambridge group. Visual acuity was tested at distance and near by rows and single optotypes with the refractive error corrected. Glasses, if needed, were worn for a minimum of 1 month before treatment was started. The initial visual acuity was recorded by one examiner and the final visual acuity by a different examiner who had no knowledge of the initial response.

'Treatment consisted of viewing an apparatus on which any one of a range of high contrast, sharp-edged gratings were slowly rotated at 1 revolution per minute (r.p.m.) behind a transparent cover on which drawing games were played to ensure the child's attention to the stimulus'. ${ }^{23}$ The nonamblyopic eye was occluded only during the actual treatment sessions.

Each child was given 5 treatment sessions of 7 to 14 minutes, and then progress was assessed. Five

Correspondence to $\mathrm{Dr}$ J. D. A. Carruthers, 2550 Willow Street, Vancouver, British Columbia, Canada V5Z 3 N9. sessions were chosen because the initial reports indicated that 'those who respond well to this treatment usually do so within the first two or three treatments'. ${ }^{1}$ The longest interval between treatment sessions was 2 weeks, and then only because illness prevented 3 children from following the weekly schedule.

Overall we studied 30 patients $(17$ male, 13 female) with an age range of 3 years 2 months to 9 years. Twelve patients had amblyopia of the right eye and 18 had amblyopia of the left eye.

\section{Results}

Eight of the 30 patients gave unreliable responses and so were excluded from the series. The remaining 22 patients included 16 (group A) who had had previous treatment for amblyopia and 6 (group B) who had not.

Table 1 shows the types of amblyopia treated in each group and Tables 2 and 3 analyse the results in group A and group B respectively.

A total of 6 patients, 2 with anisometropic, 2 with strabismic and anisometropic, and 2 with strabismic amblyopia treated with the gratings method showed more than 2 lines of improvement in linear visual acuity. Surprisingly, 4 of these patients were in group A and 2 in group B.

\section{Discussion}

Many variables exist in testing visual acuity in children. The reliability of responses depends on their understanding of the test and on the amount 
Table 1 Amblyopia types and treatment

\begin{tabular}{|c|c|c|c|}
\hline & Group A & Group B & \\
\hline $\begin{array}{l}\text { Types of } \\
\text { amblyopia }\end{array}$ & $\begin{array}{l}\text { Previous } \\
\text { treatment }\end{array}$ & $\begin{array}{l}\text { No previous } \\
\text { treatment }\end{array}$ & $\begin{array}{l}\text { Total no } \\
\text { of patients }\end{array}$ \\
\hline Strabismic (S) & $6(37.5 \%)$ & $2(33 \cdot 33 \%)$ & $8(36 \cdot 36 \%)$ \\
\hline $\begin{array}{l}\text { Strabismic }+ \\
\quad \text { anisometropic (SA) }\end{array}$ & $8(50 \%)$ & $1(16 \cdot 67 \%)$ & $9(40.91 \%)$ \\
\hline Anisometropic (A) & $2(12 \cdot 5 \%)$ & $3(50 \%)$ & $5(22.73 \%)$ \\
\hline Totals & 16 & 6 & 22 \\
\hline
\end{tabular}

Table 2 Analysis of results: group A, patients who had previous treatment

\begin{tabular}{|c|c|c|c|c|c|}
\hline $\begin{array}{l}\text { Age of } \\
\text { patient }\end{array}$ & $\begin{array}{l}\text { Type of } \\
\text { amblyopia }\end{array}$ & Fixation & $\begin{array}{l}\text { Pre- } \\
\text { treatment } \\
\text { visual } \\
\text { acuity }\end{array}$ & $\begin{array}{l}\text { Post- } \\
\text { treatment } \\
\text { visual } \\
\text { acuity }\end{array}$ & $\begin{array}{l}\text { No. of } \\
\text { lines } \\
\text { improved }\end{array}$ \\
\hline $67 / 12$ & $\mathbf{S}$ & Eccentric & $6 / 18$ & $6 / 15$ & 1 \\
\hline $54 / 12$ & $\mathbf{S}$ & Central & $6 / 21$ & $6 / 21$ & 0 \\
\hline $58 / 12$ & $\mathbf{S}$ & Central & $6 / 15$ & $6 / 15$ & 0 \\
\hline $73 / 12$ & $\mathbf{S}$ & Central & $6 / 18$ & $6 / 18$ & 0 \\
\hline $51 / 12$ & $\mathbf{S}$ & Eccentric & $<6 / 60$ & $6 / 30$ & $1^{*}$ \\
\hline 8 & $\mathbf{S}$ & Eccentric & $6 / 60$ & $6 / 18$ & 3 \\
\hline $43 / 12$ & SA & Central & $6 / 15$ & $6 / 15$ & 0 \\
\hline $74 / 12$ & SA & Central & $6 / 12$ & $6 / 9$ & 1 \\
\hline $74 / 12$ & SA & Central & $6 / 18$ & $6 / 9$ & 3 \\
\hline $42 / 12$ & SA & Central & $6 / 21$ & $6 / 12$ & 4 \\
\hline $811 / 12$ & SA & Central & $6 / 15$ & $6 / 7 \cdot 5$ & 2 \\
\hline $311 / 12$ & SA & Central & $6 / 60$ & $6 / 60$ & 0 \\
\hline $72 / 12$ & SA & Central & $6 / 12$ & $6 / 12$ & 0 \\
\hline 7 & SA & Central & $6 / 60$ & $6 / 60$ & 0 \\
\hline $42 / 12$ & $\mathbf{A}$ & Central & $6 / 24$ & $6 / 9$ & 4 \\
\hline 9 & A & Central & $6 / 60$ & $6 / 60$ & 0 \\
\hline
\end{tabular}

*Treatment continuing. $\mathbf{S}=$ Strabismic amblyopia. $\mathbf{S A}=$ Strabismic + anisometropic amblyopia.

of interest it arouses. Better attention alone may account for several lines of improvement, as may familiarity with the test. It is hard to separate improved visual acuity from better testing conditions, increased ability to co-operate with the test, or from learning. For this reason an improved response of 2 lines or less on testing linear visual acuity was not considered adequate proof of improvement in visual acuity. It can be seen from Tables 2 and 3 that only 6 patients improved more than 2 lines with the 'gratings method', 4 in group A and 2 in group B. Two of these patients had
Table 3 Analysis of results: group B, patients who had not had previous treatment

\begin{tabular}{llllll}
\hline Age of & $\begin{array}{l}\text { Type of } \\
\text { amblyopia }\end{array}$ & Fixation & $\begin{array}{l}\text { Pre- } \\
\text { treatment } \\
\text { visual } \\
\text { acuity }\end{array}$ & $\begin{array}{l}\text { Post- } \\
\text { treatment } \\
\text { visual } \\
\text { acuity }\end{array}$ & $\begin{array}{l}\text { No. of } \\
\text { lines } \\
\text { improved }\end{array}$ \\
\hline $79 / 12$ & S & Central & $6 / 18$ & $6 / 9$ & 3 \\
$510 / 12$ & S & Central & $6 / 30$ & $6 / 30$ & 0 \\
$510 / 12$ & SA & Eccentric & $6 / 60$ & $6 / 60$ & $0 *$ \\
$511 / 12$ & A & Central & $6 / 60$ & $6 / 60$ & 0 \\
$74 / 12$ & A & Central & $6 / 15$ & $6 / 12$ & 1 \\
$510 / 12$ & A & Central & $6 / 18$ & $6 / 9$ & 3 \\
\hline
\end{tabular}

"Improving with occlusion.

strabismic amblyopia, 1 patient in each group. Two had strabismic and anisometropic amblyopia, both in group A. The other 2 patients had anisometropic amblyopia, 1 patient in each group.

Reviewing the results of this pilot study has raised many points which require further investigation in a properly controlled series. For example, one 4-year-old child had a reccurrence of strabismic and anisometropic amblyopia after occlusion therapy was stopped. Gratings treatment was tried with a good response (4 lines), but within 1 month of stopping treatment the visual acuity again relapsed. We have used 15 minutes per week occlusion combined with fine visual tasks for the past month, and visual acuity is again improving. Perhaps one of the things we shall learn from the gratings method is that considerably less occlusion than previously thought (provided it is combined with fine visual tasks) is needed to maintain optimum visual acuity during the developmental period. This would be a re-emphasis of statements that have appeared for many years, ${ }^{5-7}$ including the recent papers from Cambridge.

Anisometropic amblyopes were treated after they had worn their correction for at least 1 month. Could their continued improvement be due, at least in part, to improvement obtained simply by wearing their glasses?

\section{Conclusion}

It would appear from this pilot uncontrolled study that there are sufficient grounds for a properly controlled study to evaluate whether the gratings per se offer any advantages over conventional occlusion combined with detailed visual task work for the amblyopic eye.

This work was supported in part by the Dean's Fund, University of British Columbia, and aided by a grant from 
the Canadian National Institute for the Blind out of the E. A. Baker Foundation for the Prevention of Blindness.

\section{References}

${ }^{1}$ Watson PG, Banks RV, Campbell FW, Hess RF. A clinical assessment of a new treatment for amblyopia. In: Reinecke RD, ed. Strabismus. New York: Grune and Stratton, 1978: 133-48.

${ }^{2}$ Banks RV, Campbell FW, Hess R, Watson PG. A new treatment for amblyopia. Br Orthopt $J$ 1978; 35: 1-12.

${ }^{3}$ Banks RV, Campbell FW, Hood C. A neurophysiological approach to the treatment of amblyopia. J Physiol 1978; 275: 16.

${ }^{4}$ Campbell FW, Hess RF, Watson PG, Banks RV. Preliminary results of a physiologically based treatment of amblyopia. $\mathrm{Br} J$ Ophthalmol 1978; 62: 748-55.

${ }^{5}$ Lyle TK, Jackson S. Practical Orthoptics in the Treatment of Squint, 3rd ed. Philadelphia: Blakiston, 1949: 91.

${ }^{6}$ Weiss JB. Amblyopie à fixation excentrique et occlusion. Arch Ophtalmol (Paris) 1963; 23: 176.

${ }^{7}$ Callahan WP, Berry D. The value of visual stimulation during constant and direct occlusion. Am Orthopt $J$ 1968; 18: 73 . 